\title{
Discussion on Countermeasures for Improving Environmental Protection Awareness of Rural Residents in Xi'an Section of Nanshan Ring Road in North Foot of Qinling Mountains
}

\author{
Yunchao Ma \\ College of Urban and Environmental Science \\ Northwest University \\ Xi'an, China \\ College of Economics and Management \\ Xi'an University \\ Xi'an, China
}

\begin{abstract}
The awareness of environmental protection of the villagers in the Nanshan ring road in the northern foot of the Qinling Mountains is not high. The reason is that the income level is low, their education level is not high, and the local government's environmental education is not enough. It is necessary to promote the development of green ecological tourism agriculture and raise the income level of farmers, use psychological knowledge to carry out the education of rural residents' ecological environment and local government should strengthen the environmental education for villagers, etc., enhance their environmental awareness and promote the ecological environment protection of Great Qinling Mountains.
\end{abstract}

Keywords-Great Qinling Mountains; Villager; environmental awareness

\section{INTRODUCTION}

Environmental protection awareness research is an important perspective for studying environmental issues. It is also an important measure for environmental protection and has guiding significance for environmental behavior. As a developing country, China is in the process of rapid industrialization and urbanization. The public's environmental awareness is particularly important. Therefore, research on the public's awareness of environmental protection and seeking solutions are conducive to improving the quality of environmental protection work. Environmental awareness is influenced by many factors such as geography, economic development level, local government behavior, and individual education level. Zhu Guoping (2015) pointed out that farmers' environmental awareness is very weak due to the low level of rural productivity, the low level of education of farmers, the inaction of local governments on environmental protection issues, and the inadequacy of rural environmental regulations. [1] Fu Xiangyang and Huang Taozhen (2016) systematically analyzed the mechanism and countermeasures for ecotourism to promote residents' awareness of environmental protection. The study found that the economic benefits of ecotourism are the premise and basis for improving residents' environmental awareness. Only after the economic benefits reach a certain threshold, the improvement of residents' environmental awareness can be realized. [2] Li Xiaoyan (2017) made a survey on environmental awareness of XX residents. Later, the main research conclusions were put forward: strengthen government responsibility, tap community leaders, cultivate environmental NGOs, improve legal system construction, raise awareness of environmental protection of migrants, and raise environmental management costs. [3] Li Rui, Mei Hong, and Zhu Xi (2018) used Hanyuan Town as the research object to study the role of local residents environmental awareness and willingness in the policy design of ecological civilization construction in the region. [4] In summary, there is not much research on the environmental protection awareness of rural residents, and the difference in environmental protection awareness has obvious regional characteristics. Therefore, the research on the environmental protection awareness of the villagers in the Nanshan Ring Road of the Qinling Mountains has the ecological environment protection for Great Qinling Mountains.

The Qinling Beibei Nanshan Ring Road is located at the foot of the Qinling Mountains, about 35 kilometers away from Xi'an City. The ring line is about 85 kilometers long from east to west. It runs through the four districts of Zhouzhi, Handan, Chang'an and Lantian from west to east. The villages and towns in the ring line are densely populated, the population is concentrated, the land is fertile, and the climate is pleasant. It is suitable for planting and growing in a variety of five. The natural scenery along the way is beautiful and rich in tourism resources. It has become the first choice for weekend leisure vacations in Xi'an citizens. It has also promoted the development of surrounding farmhouses. At the same time, the surrounding environmental problems have become increasingly 
prominent. Some villagers have built low-level and low-level levels for the immediate benefit. Farmhouses, free to pick up sand in the area, build fish ponds, illegally cut down trees, and destroy the environment, resulting in great damage to the ecological environment. The villagers themselves are an important group in environmental protection and a weak group in environmental protection. It is an urgent task for Qinling to protect the environment.

\section{PRESENT SituAtion AND PROBLEMS OF}

ENVIRONMENTAL PROTECTION AWARENESS OF RURAL RESIDENTS IN NANSHAN RING ROAD OF BEILING MOUNTAINS IN QINLING MOUNTAINS

Through the visits and investigations of the villages in the counties and counties where the Nanshan Ring Road of the Qinling Mountains is located, the influencing factors of the villagers' ecological environmental protection awareness are summarized as follows:

\section{A. Rural Residents Have Lower Income Levels}

The Kuznets curve shows that when the level of economic development is low, the environmental pollution is lighter. However, the degree of deterioration will increase with economic growth; when the economy develops to a certain level, the environmental quality will gradually improve. At the same time, when people are richer, the higher the requirements for environmental quality, the better the ability to reduce the degree of environmental degradation. This actually shows that the economic foundation is an important material basis for the development of society. The "five in one" general layout of socialist construction with Chinese characteristics also proves the close relationship between economic construction and ecological construction. The northern foot of the Qinling Mountains is located in the urban-rural fringe. The economic development of the region is still relatively backward. The construction of ecological civilization requires the support of the economy. The overall low level of economic development makes the ecological civilization construction in the northern foot of the Qinling Mountains lack important material security.

TABLE I. 2016 PER CAPITA DisPosABLE INCOME OF VILLAGERS

\begin{tabular}{|l|l|l|l|l|l|l|}
\hline \multicolumn{1}{|c|}{ Area } & Beijing & Xi'an & Chang'an & Lantian & Zhouzhi & Hu YI \\
\hline $\begin{array}{l}\text { Per capita } 52530 \\
\text { disposable } \\
\text { income of } \\
\text { villagers }\end{array}$ & 33032 & 27038 & 16246 & 16734 & 20343 \\
\end{tabular}
b. The data comes from the website of the National Bureau of Statistics and the Xi'an Bureau of
Statistics [5][6]

It can be seen from "Table I" that the per capita disposable income of residents in Chang'an District, Lantian County, Zhouzhi County and HuYI County is lower than the average level of Xi'an in 2016, and there is also a big difference between the four places, among which Chang'an District has per capita income. The disposable income is the highest, followed by Huxian District. The per capita disposable income of Zhouzhi County and Lantian County is only half of the average level of Xi'an. The economic base determines the superstructure. The actual situation of ecological environment protection is also the same. Environmental protection investment in areas with higher development levels is also greater, while areas with lower economic development levels have less environmental protection investment. The backwardness of economic development has also led local residents to pay too much attention to immediate interests and neglect environmental protection, thus creating irreversible damage to the protection of the region.

\section{B. Local Government Environmental Protection Education Is Not Enough}

Through investigations, it was found that Chang'an District has a strong environmental protection work. The environmental protection department has carried out propaganda for the administrative villages one by one, and distributed environmental protection materials for pollution reduction and reduction. The staff of the Chang'an District Court conducted publicity and publicity on the villagers' knowledge. Under the vigorous propaganda, the villagers have a high degree of knowledge of the ecological environment and a strong awareness of environmental protection. Relatively speaking, most rural residents in other districts and counties have insufficient knowledge of environmental protection. For example, more than $60 \%$ of farmers cannot answer the idea of digging for sand and borrowing soil. The damage of fish ponds, $30 \%$ of farmers do not know the harm of pesticides to water and soil. It is illegal to use more than $50 \%$ of the villagers who believe that it is illegal to use the basic farmland to develop forestry and fruit industry and digging ponds to raise fish. Nearly $10 \%$ of the villagers chose not to know, and nearly $40 \%$ of the villagers said they were illegal, but this behavior is more common.

\section{The Level of Education Is Not High}

The degree of education and the awareness of environmental protection are positively related. Generally speaking, the more people with lower education level, the more difficult it is to accept new ideas, the difficulty in understanding the harm of environmental pollution and their own responsibilities, and the attitude of environmental protection is relatively negative. In the survey, we found that most of the young villagers went out to work, most of the left-behind villagers were elderly, and the education level was not high. Among the residents under 35 years old, 75\% were junior high school and below. The survey found that although the villagers believe that enterprises and individuals are the main factors causing environmental pollution, more than $70 \%$ of the villagers believe that environmental protection is mainly the responsibility of the government, followed by enterprises and individuals; environmental pollution will cause huge losses to future generations. The hazards of many villagers said they had not thought about it. This also proves that the low level of education leads to their weaker ability to accept environmental knowledge, fewer channels, and weaker environmental responsibility. 


\section{COUNTERMEASURES FOR IMPROVING THE ENVIRONMENTAL PROTECTION AWARENESS OF RURAL RESIDENTS}

Environmental awareness is an important part of the quality of the people. The level of public awareness of environmental protection directly affects the formulation and implementation of national environmental protection policies. In combination with the status quo and problems of villagers' awareness of environmental protection in the Nanshan ring road in the northern foot of the Qinling Mountains, it is necessary to raise the level of environmental awareness and strengthen environmental protection.

First, promote the development of green ecological tourism agriculture and raise the income level of farmers

General Secretary Xi Jinping said that "green mountains and green hills are Jinshan Yinshan". For farmers, they must let them feel that the ecological environment is closely related to their vital interests. Only by protecting the ecological environment can we obtain more income. This will enhance farmers' awareness of environmental protection and put it into action. At present, we should vigorously promote green ecological tourism agriculture, improve agricultural production conditions through this new type of ecological tourism with agriculture and rural areas as carriers, implement comprehensive development of ecological agriculture, improve the quality of ecological environment, and achieve sustained growth in agricultural production and farmers' income in order to achieve the three major benefits of ecological, economic and social integration.

Second, local governments should strengthen environmental education for villagers through various channels.

In rural areas, due to the influence of concept and education level, farmers lack the initiative to learn environmental protection knowledge. Therefore, local government's publicity and education on environmental protection knowledge is very important. Local governments should give full play to the role of environmental protection, the judiciary and the villagers' organizations. On the one hand, they should educate the villagers through television, radio, and villagers' meetings. On the other hand, they should also directly teach the villagers through face-to-face methods. The majority of the villagers are educated about their life, production related environmental protection knowledge, environmental laws, regulations, environmental protection skills, etc., to improve the environmental awareness of the villagers.

Third, the use of psychological knowledge to educate rural residents about the ecological environment

The famous "broken window theory" in psychology is about a house. If the window is broken, no one will fix it. After a while, other windows will be inexplicably broken. This is related to people's psychological trajectory, flock effect, Follow the crowd. Similarly, the psychologist Wilson reminded the park's managers to replace the previously boring and in-humanized statements with poetic and beautiful warnings. Since then, the situation in the park has changed dramatically. Later, he explained this phenomenon, and his words were called "the principle of flower protection." Broken window theory emphasizes the external environment to educate people. The "lake flower principle" emphasizes the inner spiritual education. The commonality of the two is that external harmony must be unified with the inner thank-you. In the process of environmental education, such psychological knowledge should be used to grasp the psychology of the villagers and improve the effectiveness of environmental publicity and education.

\section{CONCLUSION}

Affected by factors such as low income level, low education level and insufficient environmental education of local governments, the awareness of ecological environment protection of rural residents in the surrounding areas of the Nanshan Ring Road in the northern foot of the Qinling Mountains needs to be improved. Green ecological tourism agriculture development, improve farmers' income level, use psychological knowledge to educate rural residents' ecological environment, local governments strengthen environmental education for villagers, etc., enhance their environmental awareness and promote ecological protection of Great Qinling Mountains.

\section{REFERENCES}

[1] Zhu Guoping. Analysis of the main reasons for farmers' weak environmental awareness, theoretical observation, July 2015.

[2] Fu Xiangyang, Huang Taozhen. Mechanisms and Countermeasures for Ecotourism Affecting Environmental Awareness of Residents, Statistics and Decision Making, December 2016.

[3] Li Xiaoyan. Research on Environmental Protection Consciousness of Residents in the Perspective of Social Governance - Based on Survey Data of XX City, Science and Economy Society, December 2017.

[4] Li Rui, Mei Hong, Zhu Xi. Research on the Status Quo of Environmental Protection, 2018.

[5] Consciousness of Residents in Key Ecological Functional Areas of Qinba and Countermeasures for the Study of Time Financial. January.

[6] Website of the National Bureau of Statistics of the People's Republic of China http://www.stats.gov.cn/.

[7] Xi'an Bureau of Statistics website: http://tjj.xa.gov.cn/ptl/index.html. 